\title{
Improving User Engagement and Social Participation of Elderly People Through a TV and Tablet-Based Communication and Entertainment Platform
}

\author{
Jakob Doppler ${ }^{1(\otimes)}$, Christian Gradl ${ }^{1}$, Sabine Sommer ${ }^{2}$, \\ and Gernot Rottermanner ${ }^{1}$ \\ 1 Institute for Creative Media Technologies, St. Pölten UAS, St. Pölten, Austria \\ jakob.doppler@fhstp.ac.at \\ 2 Ilse Alt Institute on Social Inclusion Research, St. Pölten UAS, St. Pölten, Austria
}

\begin{abstract}
Maintaining healthy relationships and companionship are major challenges to prevent potentially harmful effects of loneliness and social isolation in older age. Therefore, to foster participation and user engagement of elderly people in online communication and entertainment the user experience of devices and services need to be improved substantially. This paper discusses a participatory design approach to design and implement a TV and tablet-based communications and entertainment platform called BRELOMATE. The results of a field study with 30 elderly people over five months shows that each users was online for $37.0 \mathrm{~h}$ and played the card game service for $23.3 \mathrm{~h}$ on average over the course of 8 weeks.
\end{abstract}

Keywords: Older user engagement $\cdot$ Social participation

Senior citizens $\cdot$ User centered design $\cdot$ Multi-device $\cdot$ Tablet $\cdot$ TV

\section{Introduction}

Population ageing is a key societal challenge in western countries. The EU Ageing Report estimates that the demographic old-age dependency ratio (people aged 65 or above relative to those aged 15-64) will increase from $27 \%$ to $50 \%$ until 2060 because of declining fertility rates and increasing live expectancy [5]. With studies showing that $17 \%$ of people aged 80 or over are affected by social isolation, maintaining healthy relationships and participation in communities are major issues [4]. Although mobile devices and online services become the primary means for information access, communication and entertainment the older population is often excluded. To deal with these problems a wide range of assisting technologies are developed and tested in research projects. Despite the intensive research efforts only few systems make it to the market [6]. Common pitfalls are again a lack in user acceptance and wrong assumptions about the target group as well as financial and economic issues, which hinder a successful launch.

(C) The Author(s) 2018

K. Miesenberger and G. Kouroupetroglou (Eds.): ICCHP 2018, LNCS 10897, pp. 365-373, 2018.

https://doi.org/10.1007/978-3-319-94274-2_51 
A first major step in overcoming design challenges is a user centered design (UCD) approach that involves the older target group early in the idea generation and conceptual phase and evaluates a products or services' success based on userdriven hypotheses and user engagement metrics. While this may seem obvious, technologies for and with the elderly are often developed with a problem-oriented approach towards aging and defined around negative values such as a decline in social and physical activities as well as a higher demand of health and care needs. This leads to wrong assumptions about the actual needs and desires of elderly people [11] for whom information and communication technologies should be as enjoyable as for everyone.

With BRELOMATE we propose a TV and tablet-based communications and entertainment platform that fosters user engagement and promotes social participation among older people. Therefore, this paper discusses a threefold approach to improve and assess user engagement by (1) promoting high-quality interaction and user experience by participatory design (2) developing a robust and fail-safe platform with a multi-device client and a server (3) measuring interaction though an online gaming and communication scenario in a field study with 30 elderly people in 27 households over the course of half a year.

\section{Related Work}

The positive impact of social media and social interactions over online services for elderly people have been explored in several European countries [7]. Besides training and supporting both older people and care staff in social media these solutions focus mainly on tailoring devices and interfaces to users' needs. To foster older user engagement several research projects developed and examined TV platforms. FoSIBLE is a social TV platform which allows the user to share messages and play games over a SmartTV and tablet [1]. The technology used for user interface and navigating interactive TV content is Hybrid Broadcast Broadband Television (HBBTV) which fails to address requirements for a highquality user experience. According to analysts ${ }^{1}$ especially steaming media player such as Google Chromecast, Amazon Fire TV, Apple TV and Roku share the Smart TV market. GeTVivid is a platform which offers services to elderly to support social and informal care and underlines the potential for gamification on peer-to-peer (P2P) exchange platforms [8]. However, besides proposing a reward system with badges to increase user' motivation to actively participate there is no in-depth analysis of usability and user engagement.

A study of the acceptance of TV-based game platforms and simple games as an remote cognitive evaluation instrument [10] shows a $43 \%$ user-friendliness towards TV as a platform compared to smartphones with $29 \%$ and $\mathrm{PC}$ with $24 \%$ ( $\mathrm{n}=21,65-90$ years old). $91 \%$ of all participants stated that the TV is a very easy to use device and $75 \%$ would use TV-based gaming services again. Nevertheless, the tested games were mostly puzzles, quizzes and memory games and did not involve P2P communication. Despite the range of research

\footnotetext{
${ }^{1}$ http://www.parksassociates.com/blog/article/pr-08232017.
} 
projects, only a few systems for social participation are available close to or on the market. Media4Care ${ }^{2}$ offers a tablet solution to improve the communication between elderly citizen and their relatives as well as their caretakers. Senior Oscar $^{3}$ is one of many mobile application that integrates video chat and photo sharing combined with an elaborate interface and remote configuration. However, it lacks sophisticated services. The leading IT companies such as Google, Microsoft and Apple seem to make no effort to design and offer solutions that focus specifically on older peoples' needs. Technical barriers such as complex interaction metaphors (e.g. multi-level menu hierarchies, button with multiple states), high information density and overall poor usability prevent them from participation [9].

\section{Participatory Design Methodology}

The first pillar in promoting user engagement and social participation in online platforms involves participatory design. BRELOMATE was developed with an iterative user centered design process. Early focus groups in the beginning of the project showed that online communication and entertainment are important to older people [2].

The result of the concept phase was a multi-device platform that consists of a potentially available TV with a set-top box for visualization and a tablet for control. Watching TV is one of the most popular leisure activities for elderly people at home. By facilitating the TV, we integrate the BRELOMATE platform into a familiar environment and extend its functionality with bi-directional communication. The first services implemented on the platform were the turn-based card game Schnapsen, a videochat application called Plaudern, an elaborated contact management and a help section involving FAQ and remote help. All services work with embedded video-conferencing functionality and are only accessible in a direct interaction scenario with a distant companion or co-player.

Multiple focus groups and user tests ensured that not only high-level requirements but also specific characteristics of the interaction design were up for discussion. For instance, the tablet as a control unit was considered as an input device in favor of more natural tangible interfaces such as a NFC-based deck for card games. The older users agreed early that the tablet works as a "remote control for the TV where the menu could be navigated and notifications and events are displayed" [3].

In a focus group, the seven test participants ( 4 female and 3 male) were presented three clickable HTML-prototypes of menu interaction concepts on both tablet and TV (see Fig. 1). They had to solve tasks such as adding new contacts or starting a Schnapsen game session. Finally they had to choose a winner between concept A "short code selection" that allowed navigating with speed dialing, concept B "thumb navigation" that uses preselecting using ones thumbs and confirming by pressing an OK button or concept $\mathrm{C}$ "mirrored screen" that

\footnotetext{
${ }^{2}$ https://www.media4care.de/.

${ }^{3}$ https://www.oscarsenior.com/.
} 
duplicates most menu elements on both tablet and TV screens. In the end concept $\mathrm{C}$ was chosen with four votes for further development because of the similar spatial arrangement of menu elements that embodied the least cognitive effort on the test participants.

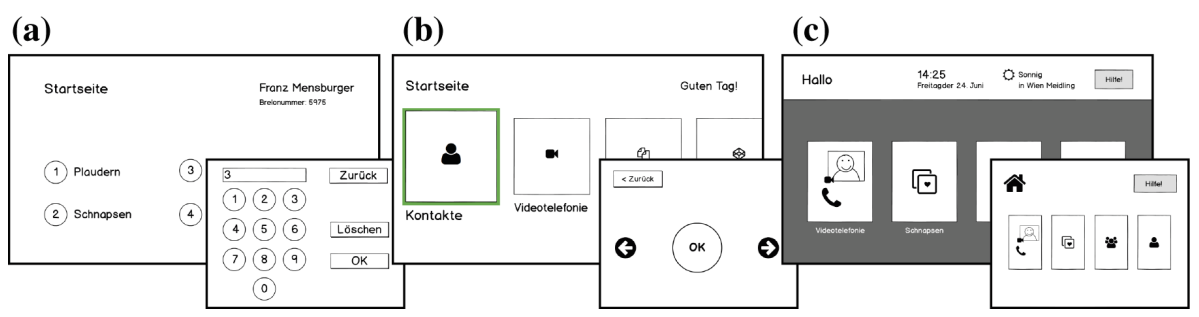

Fig. 1. Three interaction concepts presented at a focus group: (a) A "short code selection", (b) B "thumb navigation" and (c) C "mirrored screen". 4 out of 7 test participants selected concept C.

\section{Platform Architecture and Development}

As a second pillar user-engagement also sparks from robust and fail-safe design of the platform architecture. BRELOMATE is a distributed entertainment and communication platform. It is based on a central Java EE backend server and multi-device client interacting with the TV in each household. Each client setup consists of a control tablet and a set-top box that connects to the TV for visualization. Each setup requires Internet access with a WIFI network, a TV device with HDMI input and a webcam to connect to the set-top box. Both tablet and the set-top box run on the Android operating system (see Fig. 2). The main application logic is running on the Android set-top box which is responsible for the content on the TV. The tablet acts as the control unit and only handles UI related logic. It only communicates with the set-top box and does not handle any network communication to the server backend. This decision was made to prevent inconsistent application states across the devices.

To guarantee a seamless user experience and high interaction quality of the dual-screen client (tablet and set-top box) required customization of software on three layers: The BRELOMATE Android Applications and BRELOMATE framework run on top of a modified Android system. It is not a custom build of the Android OS but rather a set of system changes of the default Android OS. The configuration includes changes to adapt the UI and disable basic user interactions such as the tablets main menu for accidentally navigating out of the BRELOMATE platform. Additionally the client devices only allows to boot into and operate BRELOMATE applications and services. All rights and privileges to access the system settings or navigate to non-certified applications are permitted. Therefore, most of the preinstalled applications which come with Android such as Google Play Store, Google Play Services and email are disabled or removed. 


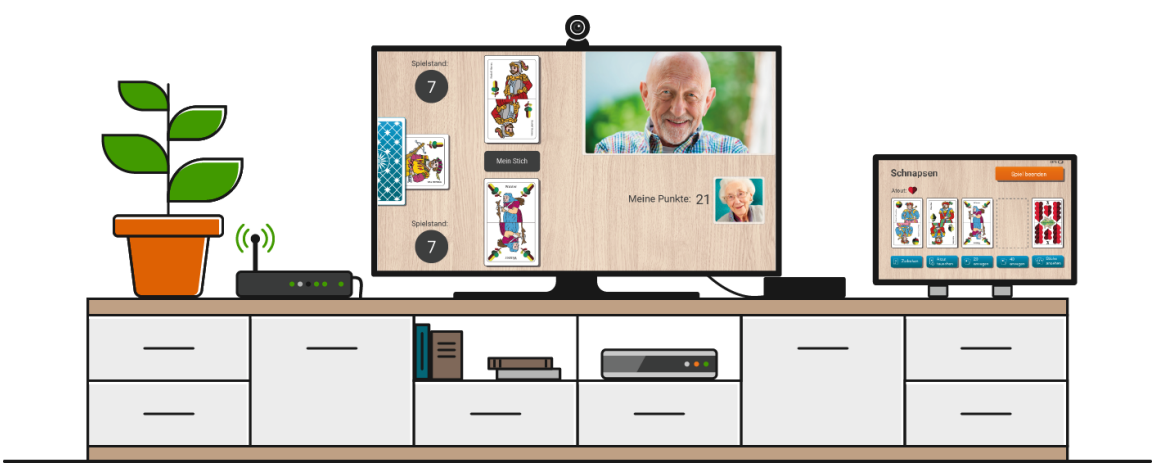

Fig. 2. The BRELOMATE client system consisting of a set-top box connected to a TV for visualisation and a tablet client mainly for control. The screens show the turnbased card game service Schnapsen with the open game table and integrated videoconferencing on the TV and each players individual hands on their tablets.

These restrictions are necessary to ensure a consistent and unified user experience across all BRELOMATE services. A self-healing mechanism allowed all parts of the system to fully recover in any state in case of Internet breakdown, power outage or battery drain of the tablet. The older users were instructed to turn off the whole setup whenever they felt for it. In the current state the platform is shipped with four preinstalled applications: the videoconferencing service Plaudern, the card game Schnapsen, contact management and the help section with FAQ and remote video support and video tutorials. An additional user interface guidelines and stylesheet were developed to guarantee a consistent look\&feel across all screens, menus and interface elements.

\section{$5 \quad$ Field Trial Design and Results}

We deployed BRELOMATE in a 5-month field trial with 27 participating households and 33 participants at start. 3 participants had to quit because of technical problems during the installation, the third because of private circumstances. 30 of these finished the field trial (see Table 1 for demographics and characteristics of the trial sample). The main goals were to test the robustness, applicability, and feasibility of the platform in a real world scenario and assess and evaluate the usability of the platform and the deployed online communication and entertainment services. All older users were made aware that data was only collected during their voluntary participation in the field trial and no private data and media was used without their prior consent. The field test was scaled into time slots with 4 to 6 participants with a participation of $6-12$ weeks. The test started with 4 participants for 2 weeks and was then increased up to 19 participants by 3 overlapping slots. This design allowed to fix technical issues which occurred at the beginning in the first time slot. 
Table 1. Description of field trial sample with 30 older residents in 27 households.

\begin{tabular}{l|l|r}
\hline \multicolumn{2}{l}{ Variables } & $\mathrm{N}=30(\%)$ \\
\hline \multirow{2}{*}{ Gender } & Female & $15(50.0 \%)$ \\
\cline { 2 - 3 } Age Mean 71.8 (SD5.7) & Male & $15(50.0 \%)$ \\
\cline { 2 - 3 } & $50-64$ & $4(13.3 \%)$ \\
\cline { 2 - 3 } & $65-74$ & $15(50.0 \%)$ \\
\cline { 2 - 3 } Media usage & $75-84$ & $11(36.7 \%)$ \\
\hline & High TV usage & $24(80.0 \%)$ \\
\cline { 2 - 3 } & First time tablet usage & $17(56.7 \%)$ \\
\cline { 2 - 3 } & Mobile phone available & $26(86.7 \%)$ \\
\cline { 2 - 3 } & Laptop available & $27(90.0 \%)$ \\
\hline
\end{tabular}

In order to quantify the user experience a logging and user tracking framework called Mixpanel ${ }^{4}$ was integrated. For quantitative research 270,000 structured data points, defined as single user interaction events, were collected. Figure 3 shows some recorded key performance indicators of the BRELOMATE platform: Overall the 30 participants spent a total of $1108.6 \mathrm{~h}$ on the platform and used the main service, the turn-based card game Schnapsen, for $699.7 \mathrm{~h}$ $(63.1 \%)$ in 19 weeks. The rest of the sessions sum up to getting used to the system, video-only conversation and looking for players during meeting hours.

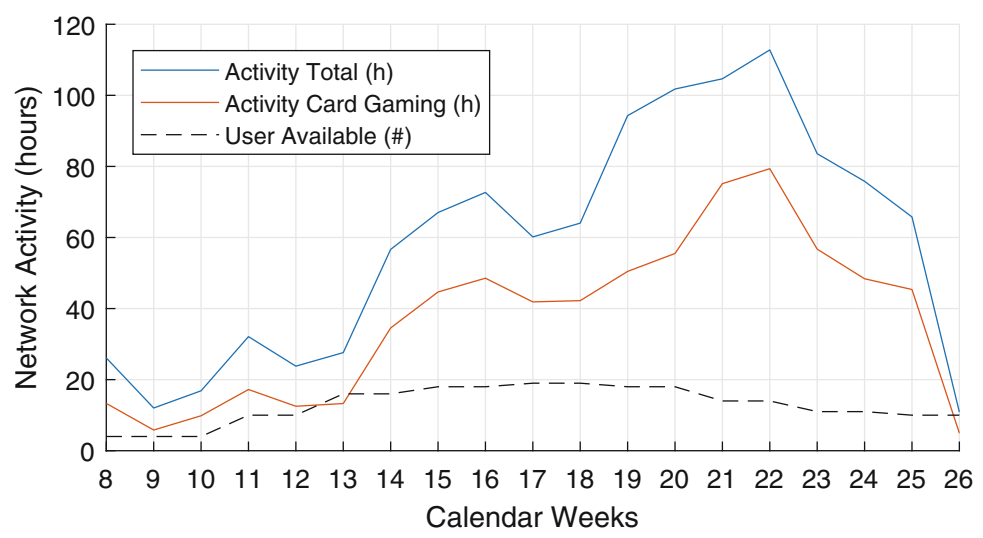

Fig. 3. Brelomate network monitoring with total and gaming activity (hours) and number of users available for entertainment and communication per calendar week.

A single user chart individual gaming result can be assessed. Figure 4 shows that participant \#23 initially started with little hours of gameplay and game

\footnotetext{
${ }^{4}$ https://mixpanel.com/.
} 


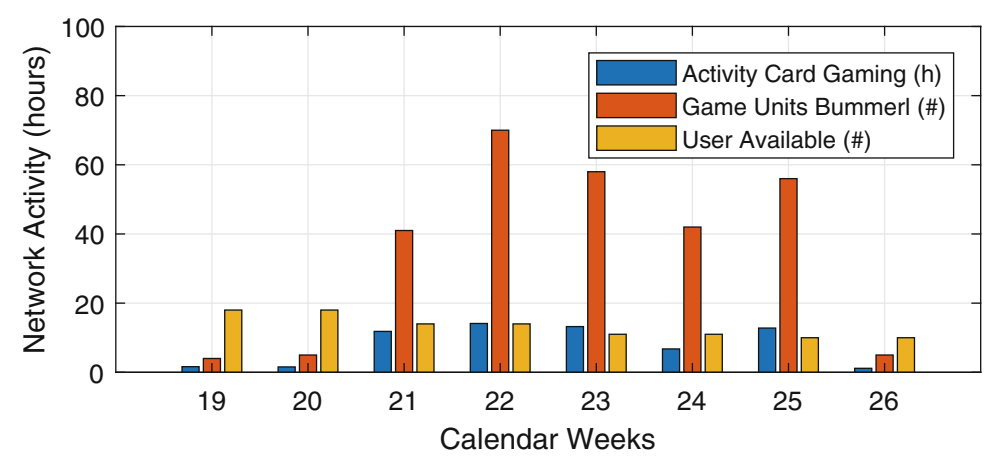

Fig. 4. Single user (\#23) game usage statistics.

unit (in Schnapsen they are called Bummerl). Throughout the weeks the play time increased but the number of games and game units (Bummerl) per hours increased from initial 2.45 (week 19) to 4.9 (week 22) to 6.2 (week 24). This indicates a steep learning curve and increased user engagement. As a side effect we also visually perceive changes in usage patterns. When asked, the participant indicated he was ill in week 25 and could not participate as much as he wanted to. For qualitative assessment a set of user experience hypotheses were formulated and examined. Although $56.6 \%$ of participants never used a tablet before and had no experience with interactive TV, they thought BRELOMATE was easy to use with $86.7 \%$ strongly agreeing and $13.3 \%$ agreeing on a 4 -point Likert scale. All participants agreed in the final questionnaire that using BRELOMATE was a fun experience and all of them would use a commercial service if it was available yet.

\section{Conclusion}

We presented a TV and tablet-based communications and entertainment platform that fosters user engagement and promotes social participation among older people. During a 5 month field trial 30 participants were able to use BRELOMATE on their own after the initial setup. Users spent on average $4.5 \mathrm{~h}$ each week during their 8 weeks period on the platform with a mean game time of 2.9 h. During questionnaire all users would have wanted to keep their prototypical client after the trial period. These results show that a participatory design process involving the users at an early concept stage of an online communication and entertainment product or service is crucial for promoting and fostering user engagement in social networks. In the future more services in the areas of tele-health, community care and municipal services will be examined.

Acknowledgement. The authors would like to thank the study participants and our partner Kabelplus GmbH. This work is supported by the Benefit programme of the Austrian Research Promotion Agency (FFG) under grant agreement No. 850849 (BRELOMATE 2) and No. 862054 (UmBrello). 


\section{References}

1. Alaoui, M., Lewkowicz, M., Seffah, A.: Increasing elderly social relationships through TV-based services. In: Proceedings of the 2nd ACM SIGHIT International Health Informatics Symposium, IHI 2012, pp. 13-20. ACM, New York (2012). http://doi.acm.org/10.1145/2110363.2110369

2. Doppler, J., Rottermanner, G., Sommer, S., Pflegerl, J., Judmaier, P.: Design and evaluation of a second screen communication and gaming platform to foster teleparticipation of the socially isolated elderly. In: Wichert, R., Klausing, H. (eds.) Ambient Assisted Living. ATSC, pp. 3-13. Springer, Cham (2016). https://doi.org/10. 1007/978-3-319-26345-8_1

3. Doppler, J., Sommer, S., Gradl, C., Rottermanner, G.: BRELOMATE - a distributed, multi-device platform for online information, communication and gaming services among the elderly. In: Miesenberger, K., Bühler, C., Penaz, P. (eds.) ICCHP 2016. LNCS, vol. 9758, pp. 277-280. Springer, Cham (2016). https://doi. org/10.1007/978-3-319-41264-1_37

4. Eiffe, F.F.: Soziale Lage aelterer Menschen in Oesterreich. Technical report Band 11, Bundesministerium fuer Arbeit, Soziales und Konsumentenschutz, Wien (2012)

5. European Commission, Directorate-General for Economic and Financial Affairs, EC, Economic Policy Committee of the European Communities: The 2015 ageing report: economic and budgetary projections for the 28 EU Member States (20132060). Publications Office, Luxembourg (2015). oCLC: 948763579

6. Haslwanter, J.D.H., Fitzpatrick, G.: Why do few assistive technology systems make it to market? The case of the HandyHelper project. Univ. Access Inf. Soc. 16(3), 755-773 (2017). https://doi.org/10.1007/s10209-016-0499-3

7. Morton, T.A., Wilson, N., Haslam, C., Birney, M., Kingston, R., McCloskey, L.G.: Activating and guiding the engagement of seniors with online social networking. J. Aging Health (2016). https://doi.org/10.1177/0898264316664440

8. Moser, C., Peterhansl, M., Kargl, T., Tscheligi, M.: The potentials of gamification to motivate older adults to participate in a P2P support exchange platform, pp. 655-660. ACM (2015). http://dl.acm.org/citation.cfm?id=2793107.2810326

9. Nef, T., Ganea, R.L., Müri, R.M., Mosimann, U.P.: Social networking sites and older users - a systematic review. Int. Psychogeriatr. IPA 25(7), 1041-1053 (2013)

10. Rivas Costa, C., Fernández Iglesias, M.J., Anido Rifón, L.E., Gómez Carballa, M., Valladares Rodríguez, S.: The acceptability of TV-based game platforms as an instrument to support the cognitive evaluation of senior adults at home. PeerJ $\mathbf{5}$ (2017). https://www.ncbi.nlm.nih.gov/pmc/articles/PMC5214704/

11. Vines, J., Pritchard, G., Wright, P., Olivier, P., Brittain, K.: An age-old problem: examining the discourses of ageing in HCI and strategies for future research. ACM Trans. Comput. Hum. Interact. 22(1), 2:1-2:27 (2015). https://doi.org/10.1145/ 2696867 
Open Access This chapter is licensed under the terms of the Creative Commons Attribution 4.0 International License (http://creativecommons.org/licenses/by/4.0/), which permits use, sharing, adaptation, distribution and reproduction in any medium or format, as long as you give appropriate credit to the original author(s) and the source, provide a link to the Creative Commons license and indicate if changes were made.

The images or other third party material in this chapter are included in the chapter's Creative Commons license, unless indicated otherwise in a credit line to the material. If material is not included in the chapter's Creative Commons license and your intended use is not permitted by statutory regulation or exceeds the permitted use, you will need to obtain permission directly from the copyright holder. 